\title{
Occupational stress and sleep quality in professors of the health area
}

\author{
Estresse ocupacional e qualidade do sono em docentes da área da saúde
}

Aline Rodrigues de Sousa ${ }^{1}$, Rayane Bezerra Santos ${ }^{1}$, Rodrigo Marques da Silva ${ }^{1}$, Carla Chiste Tomazoli Santos ${ }^{1}$, Victor Cauê Lopes ${ }^{2}$, Fernanda Carneiro Mussi ${ }^{3}$

Objective: to analyze the relationship between occupational stress and sleep quality in health professors. Methods: this is a cross-sectional study using a sociodemographic, occupational and Occupational Stress Scale and Pittsburg Sleep Quality Index. Results: male professors (57.9\%), married (47.4\%), and children $(52.6 \%)$, living with the family $(89.5 \%)$ and with a mean age of 34.7 years old predominated. In the sample, $63.2 \%$ had low-stress level and $57.9 \%$ had poor sleep quality, which was more affected by daytime sleepiness, sleep disturbances, and sleep duration. There was a significant and positive correlation between general stress level and use of sleeping medication. Conclusion: there was low level of stress and low quality sleep. Daytime sleepiness, sleep disturbances, and sleep duration are the factors that contribute most to the poor quality of sleep of health professors.

Descriptors: Occupational Health; Stress, Psychological; Faculty.

Objetivo: analisar a relação entre estresse ocupacional e qualidade do sono em docentes da área da saúde. Métodos: estudo transversal realizado por meio de um questionário sociodemográfico, ocupacional e da Escala de Estresse no Trabalho e Índice de Qualidade de Sono Pittsburg. Resultados: predominaram docentes homens $(57,9 \%)$, casados $(47,4 \%)$, com filhos $(52,6 \%)$, que residem com a família $(89,5 \%)$ e com 34,7 anos em média. Da amostra, $63,2 \%$ apresentaram baixo nível de estresse e $57,9 \%$, baixa qualidade do sono, sendo essa mais afetada pela sonolência diurna, distúrbios do sono e duração do sono. Houve correlação significativa e positiva entre nível de estresse geral e uso de medicações para dormir. Conclusão: baixo nível de estresse e baixa qualidade do sono. Constata-se que, a sonolência diurna, os distúrbios do sono e a duração do sono os fatores que mais contribuem para a baixa qualidade do sono dos docentes da área de saúde.

Descritores: Saúde do Trabalhador; Estresse Psicológico; Docentes.

\footnotetext{
${ }^{1}$ Faculdade de Ciências e Educação Sena Aires. Valparaíso de Goiás, GO, Brazil.

${ }^{2}$ Faculdade do Vale do Juruena. Juína, MT, Brazil.

${ }^{3}$ Universidade Federal da Bahia. Salvador, BA, Brazil. 


\section{Introduction}

This paper contributes for the mental health changes of the individual from several contexts involved: from specific factors, such as exposure to toxic agents, to the junction of factors related to work organization, such as division and subdivision of tasks, politics of people management and the hierarchical structure. Also, the continuous technological, economic, political, cultural and social changes present in society have a direct relationship with the world of work in its various sectors, including the education ${ }^{(1-2)}$.

In this context, the teaching practice has been opting for more qualified professionals and able to attend the high number of students with all their needs and particularities, requiring new adaptations by the professors. The teaching work involves activities with intense interactions among people, which can produce results that affect not only the expectations of students but especially the health of the professor. Also, the professor lives with situations such as high performance, work for extended periods and longer time of travel in the home-work routes and vice versa, which significantly changed human sleep patterns and consequently led to increased stress levels, compromising the health and well-being of workers. These typical situations of work environment and life in large cities influence professors' sleep habits, which can lead to increased levels of stress at work ${ }^{(2-3)}$.

Work-related stress is understood as an answer to situations in which the individual perceives his environment as threatening personal and professional fulfillment needs or his physical and mental health, hampering interaction with work and the environment. Stress affects $90.0 \%$ of the world population, and only in Brazil, $70.0 \%$ of the population suffers from this disease, and $30.0 \%$ of the population perceives high levels of stress. Faced with these data, teaching is considered to be one of the most stressful professions, because "producing knowledge" has become an exhausting activity, with clear repercussions on teachers' health, especially on the quality of their sleep $^{(4)}$.

Sleep quality is a relevant issue for public health. According to the American Academy of Sleep Medicine, normal sleep is essential to have a productive waking period and a permanent sense of well-being. However, there is a difficulty in finding a definition for normal sleep since each individual has his particularities, whether with biological or mental origin ${ }^{(5-7)}$. In a study carried out with 230 professionals from the private network of Rio Grande do Sul, the problems and difficulties related to sleep reached $59.0 \%$ of the interviewees in the last six months of the year, and this frequency has been higher due to concerns for $36.0 \%$ of the interviewed professors. These problems related to sleep have a direct relationship with the excessive amount of activities and tasks and the feeling of impotence to deal with them ${ }^{(8)}$.

Such factors triggering problems in sleep quality of higher education professors were also found in a study carried out with 279 elementary school teachers, in the state network of a city of São Paulo. Of the 279 teachers evaluated, 150 (53.8\%) had poor sleep quality associated with the presence of physical and emotional symptoms, the performance of several activities and the feeling of difficulty to fulfill all the tasks $^{(9)}$. Also in these studies, most of the disorders are characterized by insomnia by the difficulty in initiating or maintaining sleep; hypersomnia manifested as amount of sleep and excessive daytime drowsiness; parasomnia and alteration of the sleep-wake cycle. The difficulty of teachers in initiating and/or maintaining non-restorative sleep is highlighted, which may affect the quality and quantity of sleep ${ }^{(8-9)}$.

Although occupational stress may contribute to changes in sleep pattern and quality, the opposite is also possible. Since sleep is essential for the recovery of biological and mental functions, it is possible that changes in sleep quality cause higher levels of stress at work. This can occur in teachers because to meet the demands of work and reconcile them to social and 
family life, they are deprive of a few hours of sleep during the week, which can compromise the quality of sleep and lead to occupational stress. However, although there are researches carried out with elementary school teachers ${ }^{(8-9)}$ on this topic, there are still few studies with higher education professors ${ }^{(4)}$.

Therefore, the objective of this research was to analyze the relationship between occupational stress and sleep quality in health professors.

\section{Methods}

This is a cross-sectional study, carried out at a private college in Valparaiso de Goiás, Brazil. The institution is located in the border region between the state of Goiás and the Federal District, offering technical, undergraduate and post-graduate courses in the health area.

The study population was professors of courses in the health area linked to the institution during the period of data collection. Professors linked to the institution period, with a workday of at least 20 hours/weekly classes and working in at least one undergraduate course in the nursing, pharmacy or physiotherapy area were included in the data collection. Professors on leave of any type were excluded from the research.

Data were collected between October and December 2017, through the following self-applicable instruments: Sociodemographic and occupational questionnaire of Professors; Pittsburg Sleep Quality Index (PSQI) ${ }^{(10)}$ and Work Stress Scale ${ }^{(11)}$.

The sociodemographic and occupational questionnaire was developed by the researchers, involving the following variables: date of birth (age), gender, marital status, presence of children, monthly family income and monthly expenditure (minimum salaries), sufficiency of monthly family income for maintenance, academic training, undergraduate course in which they work, time of work, postgraduate qualification, weekly working hours in the institution, work regime in the analyzed institution (hourly, partial or full), number of employment, holiday fulfillment in the last year, work shift, substance use to inhibit or stimulate sleep.

Constructed and validated in 2004, the Work Stress Scale consists of 23 items in a Likert scale with 5 points: 1 - totally disagree, 2 - disagree, 3 - partially agree, 4 - agree and 5 - totally agree. With the sum of the scores indicated in each article, the occupational stress scores are obtained and, the higher the sum, the higher the level of stress of the individual in the work environment ${ }^{(11)}$.

The Pittsburgh Sleep Quality Index was validated in 1989 with patients having sleep dysfunction compared to those without changes ${ }^{(12)}$. It was validated in Brazil ${ }^{(10)}$ with the objective of evaluating sleep quality in the last month. This instrument has 10 questions: 1 to 4 were open questions and 5 to 10 were semi-opened questions. The questions are divided into seven components: Subjective sleep quality (Question 6); Sleep latency (Questions 2 and 5a); Duration of sleep (Question 4); Usual sleep efficiency (Questions 1, 3 and 4); Sleep disorders (Questions $5 \mathrm{~b}$ to $5 \mathrm{j}$ ); Use of sleep medications (Question 7) and Daytime sleepiness and daytime disturbances (Questions 8 and 9). Question 10 is optional and will not be used in this research because it requires the presence of a roommate for analysis. The overall score is calculated by the sum of the score of each component, varying from zero to three. The maximum possible value is 21 points and the higher the score, the worse the quality of sleep. In the analysis of the components, the same logic is followed, so the higher the component score, the worse the quality of sleep of the population. The instructions described in a survey with health professionals were followed to convert the answers obtained in each question to a scale of zero to three ${ }^{(10)}$. The research subjects were individually approached in the work environment according to the scale of work previously obtained with the coordination of the courses. The questionnaires were delivered to the professors who had a period of up to 15 days to return them already filled. 
A database was created in the Excel (Office 2010) program for data organization which was exported to the Statistical Package for Social Science program, version 17.0. The analyses were analyzed. Categorical variables were presented in absolute and percentage values, while quantitative variables were presented in descriptive measures: minimum and maximum values, mean and standard deviation (SD). The Pearson correlation was used for continuous data to analyze the correlation between stress and sleep quality. The results were considered statistically significant if $\mathrm{p}<0.05$, and normality was analyzed using the Kolmogorov-Smirnov test.

After obtaining the authorization for data collection at the research institution, the project was approved by the Ethics Committee of the proposing institution under opinion 2,411,169.

\section{Results}

The initial population of the study was composed of 24 professors from courses in the health area of the study site. Four of them did not submit the completed research protocol and one was part of the research team, leaving 19 professors as the access population.

There was a predominance of male professors (57.9\%), married (47.4\%), without children (52.6\%), living with their family (89.5\%), with a BA in Physical Therapy $(42.1 \%)$ as the main course of the sample (42.1\%). There was a predominance of professors with a master's degree (73.7\%). Moreover, in the analysis of income, it was observed that $47.4 \%$ perceive monthly family income between five and 10 minimum wages and $57.9 \%$ consider it sufficient for their maintenance.

There was a predominance of professors working as hour workers (68.4\%), with more than one employment bond (84.2\%), with two jobs as the most frequent in the sample (63.2\%). They worked all shifts (morning, afternoon and evening) (78.9\%) and took vacations in the last year (73.7\%).
Table 1 presents the sociodemographic and occupational variables that are continuous in the health professors of a private college. The teachers were on average 38.80 years old $(S D=15.53)$, working in teaching with an average of 120 months, which is equivalent to 10 years, and with an average weekly schedule of 24 hours (SD=11.27).

Table 1 - Descriptive measures for sociodemographic and occupational variables in professors of the health area of a private college

\begin{tabular}{|c|c|c|c|c|c|}
\hline \multirow{2}{*}{ Variables } & \multicolumn{5}{|c|}{ Descriptive measures } \\
\hline & Minimum & Maximum & Average & Median & $\begin{array}{l}\text { Standard } \\
\text { Deviation }\end{array}$ \\
\hline Age (years old) & 23.00 & 61.00 & 38.80 & 38.00 & 10.17 \\
\hline $\begin{array}{l}\text { Time working } \\
\text { (months) }\end{array}$ & 1.00 & 360.00 & 127.36 & 120.00 & 118.74 \\
\hline $\begin{array}{l}\text { Weekly workload } \\
\text { (hours) }\end{array}$ & 6.00 & 44.00 & 24.00 & 24.00 & 11.27 \\
\hline
\end{tabular}

There was a predominance of low level of stress $(63.2 \%)$ among the health professors. In the analysis of sleep quality, it was found that $57.9 \%$ of the professors had a low sleep quality. Table 2 shows the mean scores per domain of the Pittsburgh Sleep Quality Index among professors of a private college.

Table 2 - Averages by component of the Pittsburgh Sleep Quality Index among professors from a private college

\begin{tabular}{lcc}
\hline PSQI Component* & Average & $\begin{array}{c}\text { Standard } \\
\text { Deviation }\end{array}$ \\
\hline Subjective sleep quality & 1.05 & 0.76 \\
Sleep latency & 1.11 & 1.17 \\
Duration of sleep & 1.58 & 0.59 \\
Usual sleep efficiency & 0.00 & 0.00 \\
Sleep Disorders & 2.21 & 0.61 \\
Use of sleeping medication & 0.21 & 0.69 \\
Daytime sleepiness & 2.21 & 0.69 \\
\hline * PSQI: Pittsburgh Sleep Quality Index & &
\end{tabular}

Daytime sleepiness, sleep disturbances, and sleep duration are the factors that contribute most 
to the poor quality of sleep presented by the health professors since they had the highest averages in comparison to the others domains of the PSQI. Regarding Table 3, the results of the correlation analysis between occupational stress and sleep quality (general and component) among professors of a private college are observed.

Table 3 - Correlation between occupational stress and sleep quality among professors of a private college

\begin{tabular}{lcc}
\hline \multirow{2}{*}{ Pittsburgh Sleep Quality Index } & \multicolumn{2}{c}{ Stress } \\
\cline { 2 - 3 } & $\mathbf{R}$ & $\mathbf{p}^{*}$ \\
\hline Sleep quality (general) & 0.335 & 0.134 \\
Subjective sleep quality & 0.094 & 0.703 \\
Sleep latency & 0.206 & 0.398 \\
Duration of sleep & -0.040 & 0.872 \\
Usual sleep efficiency & 0.000 & 0.153 \\
Sleep Disorders & 0.197 & 0.419 \\
Use of sleeping medication & $0.478^{* *}$ & 0.039 \\
Daytime sleepiness & 0.371 & 0.117 \\
\hline${ }^{*} \mathrm{p}<0.05$; **Pearson's Correlation & &
\end{tabular}

The Table shows no significant association between stress scores and general sleep quality $(p=0.134)$. However, there is a significant and positive correlation between use of sleep medications and general stress level. Thus, the higher the level of occupational stress presented by the professor, the worse the quality of sleep related to the use of sleeping medications.

\section{Discussion}

The limited number of professors stands out as a limitation of the research. Therefore, it is suggested that new research be developed in other Brazilian colleges and universities with samples and/or larger populations so the working conditions of university professors in the health area and their relationship with occupational stress and quality of sleep.

The changes in the educational scenario and in the teaching-learning process are transformed according to the demands in the world of work, cultural changes and the increasing technological evolution. When associated to the individual characteristics of the professors, these conditions can cause changes in sleep throughout the professional life $\mathrm{e}^{(13)}$.

There was a predominance of male professors, married, without children, who live with the family and presented a mean age of 38.80 years old, considered young adults. In a cross-sectional study that analyzed the influence of excessive daytime sleepiness on the quality of life of 270 university professors (including those in the health area), female (52.2\%) predominated in the 30 to 39 age group (35.5\%) and married $(65.0 \%)^{(14)}$.

The sociodemographic profile between the professors and other investigations is consonant, although with a difference in the gender variable that is culturally sensitive to the undergraduate course involved. Nursing, for example, is an essentially female profession, the opposite being found in the course of medicine that is characteristically male. Although there is a change in this culturally constructed profile, different studies still demonstrate the existence of this panorama ${ }^{(14-15)}$.

As for the other variables common in studies carried out with professors, the researchers point out that a stable relationship, such as marriage, and the presence of children are elements working as a social support, stress coping strategy that helps to minimize stress and their physical and psychic effects. In this sense, the general tendency found in professors is that they are more mature and stable people, which, together with a good relationship with family and children, they have greater capacity to face personal problems and emotional conflicts ${ }^{(14-15)}$.

Also, there was a predominance of professors working in the three shifts (morning, afternoon and evening), who have been working in teaching for an average of 10 years and with an average weekly workload of 24-hours in the institution. Those who have 
more than one employment relationship, hourly, who receive between five and 10 minimum wages and took vacations in the last year are highlighted. In researches with university health professors, it was observed that the average working time in the health area was 120 months ( $\mathrm{SD}=123.00$ months) and 119 months working in the teaching area (SD=117.00 months) ${ }^{(15)}$.

In a study carried out with higher education professors from three large private universities in Porto Alegre, professionals reported that the number of hours worked is insufficient for the execution of activities, both in the hourly and in the integral regime, which leads to disproportionate demands and difficulties in meeting deadlines ${ }^{(16)}$. In addition, the accumulation of work bonds and alternating shifts are aspects that contribute to the overload of work, with activities that include: preparing and giving classes, giving extra attention to students, preparing and correcting tests, producing and publishing articles research, guide students, among others. This contributes to the development of physical and emotional symptoms of occupational stress, with a greater risk of the teacher becoming sick ${ }^{(15)}$.

Regarding to the degree, professors with master's degree $(73.7 \%)$ predominated. In a survey of 107 professors from a federal university, it was observed predominance of those with a doctorate degree $(68.2 \%)^{(15)}$. The same was verified in a survey of 270 professors from the Federal University of Rio Grande, in which $75 \%$ had a doctorate degree ${ }^{(14)}$. The predominance of professors with doctoral degrees in the studies found is due to the requirement of this degree in federal and state public institutions for investiture in the position of assistant professor. Regardless of the level (master's or doctorate degrees), professors are led to qualify with the goal of incorporating more skills and meeting educational goals. However, the higher the educational levels, the greater the predisposition to occupational stress due to the increased responsibilities assumed in the institution ${ }^{(17)}$.

Teachers' stress levels were low, but approximately one-third of the population had a high level.
A survey of 107 university professors from the state of Rio Grande do Sul showed a predominance of low stress in $93.5 \%$ of the sample ${ }^{(15)}$. Researchers point out that, despite the teacher's work environment presenting potential stressors, the social support obtained by them from the relationships with the family and children and co-workers is a strategy often used effectively by them to cope of stress. Furthermore, research shows that the acceptance of responsibilities and escape-avoidance imply lower levels of stress among university faculty ${ }^{(14-15)}$.

Professors have poor sleep quality, daytime sleepiness, sleep disturbances, and sleep duration are the factors that most contribute to poor sleep quality. In addition, in an investigation with 270 university professors, excessive daytime sleepiness was identified in $35.2 \%$ of the sample through the Epworth Sleepiness Scale ${ }^{(14)}$. Teaching is an activity that requires skill and insight to deal with a remarkable number of people with varying behaviors, various extra class activities, and intense social pressure related to the teacher's role. In this context, teachers often need to work outside the hours and institutional space, which interferes in their private life and especially in sleep. They sacrifice the time that should be spent sleeping to do the extra tasks that are required by the profession, which results in reduced sleep duration. This explains the daytime sleepiness and the low quality of sleep presented by university professors in this and other investigations $^{(14)}$.

Also, a significant correlation was found between the level of occupational stress and the poorer quality of sleep related to the use of sleeping medication. Although there is a movement towards the restructuring of academic curricula, professors still deal with work overload, the accumulation of links, the lack of capacity to deal with innovative proposals that are increasingly present in public and private institutions, and with the challenges to the processes of teaching-learning related to the gaps brought by the students in the face of the low quality of primary and secondary education ${ }^{(18)}$. It is common for situations 
such as these to outweigh the adaptive resources of teachers, leading them to occupational stress. Thus, it is possible that the individual takes more time to fall asleep or to experience insomnia, being common the use of anxiolytic and hypnotic drugs to handle this reality. This explains the correlation of teachers' stress with the decrease in sleep quality linked to the use of medication.

In this investigation, there was no association between general sleep disorders and stress in the studied group. This can be explained by the predominance of professors with low levels of stress and sleep quality. In this sense, it can be understood that, although the teaching work process is considered potentially stressful, professors use effective strategies to minimize stress at work and have a sociodemographic profile (married or having a stable union and having children) levels of stress. This panorama does not occur with the quality of sleep that seems to be affected by daily teaching and its demands. Thus, although coping strategies are effective for the control of stress, the quality of sleep remains changed. Therefore, it is necessary to better analyze the causes of changes in the pattern and quality of sleep, their consequences, and variables that may protect or promote better quality sleep for professors ${ }^{(19)}$.

\section{Conclusion}

There was a predominance of low level of stress and poor sleep quality, with daytime sleepiness, sleep disturbances, and sleep duration being the factors that contribute most to the poor quality of sleep of health professors. The decrease in sleep quality related to the use of sleeping medication resulted in higher levels of occupational stress among professors. Although the teaching work process is considered potentially stressful, most of the sample analyzed presented low levels of occupational stress, which raises the possibility of using effective strategies to cope with stressors at work.

\section{Collaborations}

Sousa AR, Santos RB and Silva RM collaborated with the conception and design, analysis and interpretation of the data, essay writing and critical review of the intellectual content. Santos CCT, Lopes V, and Mussi FC collaborated in the analysis and interpretation of the data, essay writing, critical review of the intellectual content and final approval of the final version to be published.

\section{References}

1. Jang TW, Koo JW, Kwon SC, Song J. Work-related musculoskeletal diseases and the workers' compensation. J Korean Med Sci. 2014; 29 (Suppl 1):18-23. doi: dx.doi.org/10.3346/jkms.2014.29

2. O'Donnell MP. Health promotion in the workplace. Troy: Art \& Science of Health Promotion Institute; 2017.

3. Briançon-Marjollet $A$, Weiszenstein $M$, Henri $M$, Thomas A, Godin-Ribuot D, Polak J. The impact of sleep disorders on glucose metabolism: endocrine and molecular mechanisms. Diabetol Metab Syndr. 2015; 7(25):1-16.doi: http://dx.doi.org/10.1186/ s13098-015-0018-3

4. Colacion-Quiros H, Gemora RB. Causes and effects of stress among faculty members in a state university. APJMR [Internet]. 2016 [cited June 12, 2018]; 4(1):18-27. Available from: http:// www.apjmr.com/wp-content/uploads/2016/03/ APJMR-2016.4.1.04.pdf

5. Sateia MJ. International classification of sleep disorders-third edition: highlights and modifications. Chest. 2014; 146(5):1387-94. doi: http:// dx.doi.org/10.1378/chest.14-0970

6. Peever J, Fuller PM. The biology of REM sleep. Curr Biol. 2017; 27(22):1237-48. doi: http://dx.doi. org/10.1016/j.cub.2017.10.026

7. Leite AF, Nogueira JAD. Fatores condicionantes de saúde relacionados ao trabalho de professores universitários da área da saúde: uma revisão integrativa. Rev Bras Saúde Ocup 2017; 42:1-15. doi: dx.doi.org/10.1590/2317-6369000010116 
8. Rozendo KCT, Dias CD. Possibilidades de sofrimento psíquico do professor universitário de uma licenciatura. Colloquium Hum. 2015; 11(3):126-44. doi: dx.doi.org/10.5747/ch.2014. v11.n3.h178

9. Souza JC, Galina SD, Sousa IC, Azevedo CVM. Effect of a sleep education program on sleep knowledge and habits in elementary and high school teachers. Estud Psicol. 2016; 21(4):369-80. doi: http:// dx.doi.org/10.5935/1678-4669.20160036

10. Bertolazi NA. Tradução, adaptação cultural e validação de dois instrumentos de avaliação do sono: escala de sonolência de Epworth e índice de qualidade de sono de Pittsburgh. Porto Alegre: Universidade Federal do Rio Grande do Sul; 2008.

11. Paschoal T, Tamayo A. Validação da escala de estresse no trabalho. Estud Psicol. 2004; 9(1):4552. doi: http://dx.doi.org/10.1590/S1413294X2004000100006

12. Buysse DJ, Reynolds CF, Monk TH, Berman SR, Kupfer DJ. He Pittsburgh Sleep Quality Index: a new instrument for psychiatric practice and research. Psychiatr Res. 1989; 28:193-213. doi: https://doi.org/10.1016/0165-1781(89)900474

13. Oliveira ASD, Pereira MS, Lima LM. Trabalho, produtivismo e adoecimento dos docentes nas universidades públicas brasileiras. Psicol Esc Educ [Internet]. 2017 [citado 2018 jun 12]; 21(3):60919. Disponível em: http://www.redalyc.org/ articulo.oa?id=282353802028
14. Amaro JMRS, Dumith SC. Sonolência diurna excessiva e qualidade de vida relacionada à saúde dos professores universitários. J Bras Psiquiatr. 2018; 67(2):94-100. doi: http://dx.doi. org/10.1590/0047-2085000000191

15. Kirchhof RS, Freitas EO, Silva RM, Guido LA, Costa ALS, Lopes LFD. Relations between stress and coping in federal universities nursing teachers of a Brazilian state-analytical study. J Nurs Educ Pract. 2015; 5(12):9-16.doi: https://doi.org/10.5430/ jnep.v5n12p9

16. Ligabue R. Prevalência de alterações de sono e estresse em docentes do ensino superior de uma instituição de ensino privada de Porto Alegre. Canoas: Centro Universitário La Salle; 2017.

17. Dalagasperina P, Monteiro JK. Estresse e docência: um estudo do ensino superior privado. Rev Subj. 2016; 16(1):37-51. doi: http://dx.doi. org/10.5020/23590777.16.1.37-51

18. Peres CRFB, Marin MJS, Tonhom SFR, Marques MLSF. Current challenges in nursing education: the professor's perspective. Rev Rene. 2018; 19:e3160. doi: http://dx.doi.org/10.15253/21756783.2018193160

19. Souza JC, Oliveira MLC, de Sousa IC, Azevedo CVM. Gender differences in sleep habits and quality and daytime sleepiness in elementary and high school teachers. Chronobiol Int. 2018; 35(4):486-98. doi: http://dx.doi.org/10.1080/07420528.2017.1415 921 